Tropical Journal of Pharmaceutical Research April 2015; 14 (4): 655-662

ISSN: $1596-5996$ (print); 1596-9827 (electronic)

(C) Pharmacotherapy Group, Faculty of Pharmacy, University of Benin, Benin City, 300001 Nigeria.

All rights reserved.

Available online at http://www.tjpr.org

Original Research Article

http://dx.doi.org/10.4314/tjpr.v14i4.14

\title{
Dose Determination of Activated Charcoal in Management of Amitriptyline-Induced Poisoning by Reversed-Phase High-Performance Liquid Chromatography
}

\author{
Mohammed A Alotaibi ${ }^{1}$, Amjad K Fataftah ${ }^{1}$, Khalid Alkhanbashi ${ }^{2}$, Abdlatif A Al- \\ Dhawailie $^{3 *}$, Fawaz A Alanazi ${ }^{1}$, Fowad M Khurshid ${ }^{3}$ and Mohammed S Alsultan ${ }^{3}$ \\ ${ }^{1}$ Department of Forensic Chemistry, College of Forensic Sciences, Naif Arab University for Security Sciences, ${ }^{2}$ Department of \\ Pharmacy, King Khalid University Hospital, College of Medicine, ${ }^{3}$ Department of Clinical Pharmacy, College of Pharmacy, King \\ Saud University, Riyadh, Saudi Arabia
}

*For correspondence: Email: alatif@ksu.edu.sa; Tel: +966 -11- 467 7488; Fax: +966 -11- 4677480

\begin{abstract}
Purpose: To assess the doses of activated charcoal currently used in the management of acute amitriptyline-induced drug poisoning and explore the possibility of using lower doses.

Methods: Albino male Wistar rats, weighing $200 \pm 20 \mathrm{~g}$, were used for the study. The animals were divided into four groups of eight animals each. The concentration of amitriptyline in rat plasma was measured by high performance liquid chromatography (HPLC) for dose determination of activated charcoal. Chromatograms were established with acetonitrile: $70 \mathrm{mM} \mathrm{KH}_{2} \mathrm{PO}_{4}$ buffer (60: 40, v/v) solvent system on an Xterna® ms C18 SUM column $(5 \mu \mathrm{m}, 3.9 \times 150 \mathrm{~mm})$ and $\mathrm{pH}$ was adjusted to 4.5 with ortho-phosphoric acid. Mobile phase flow rate was $1 \mathrm{ml} / \mathrm{min}$ and ultraviolet (UV) detection was at 293 $\mathrm{nm}$. Validation of the method was performed to determine its selectivity, linearity, precision, as well as limits of detection (LOD) and of quantification (LOQ).

Results: Standard curves were linear, $r^{2}=0.996$, for amitriptyline over the concentration range $10-60$ $\mathrm{ng} / \mathrm{ml}$. Recovery (98.3 to $100.85 \%$ ) was in the selected concentration range of $10-60 \mathrm{ng} / \mathrm{ml}$. The LOD and $L O Q$ of the method for amitriptyline were 0.109 and $0.332 \mu \mathrm{g} / \mathrm{ml}$, respectively. The validated method was successfully applied to measure plasma concentrations of amitriptyline and to measure the doses of activated charcoal currently used in the management of acute amitriptyline drug poisoning.

Conclusion: The proposed RP-HPLC method enables determination of amitriptyline with good separation and resolution of the chromatographic peaks. Validation revealed that the method is sensitive, accurate and selective. Using half of the standard dose of the activated charcoal gave a comparable effect to the standard dose in reducing drug concentration in the blood. While, using quarter of the standard dose of activated charcoal does not have a cleared effect.
\end{abstract}

Keywords: Amitriptyline, Activated charcoal, Drug poisoning, Reversed-phase high-performance liquid chromatography

Tropical Journal of Pharmaceutical Research is indexed by Science Citation Index (SciSearch), Scopus, International Pharmaceutical Abstract, Chemical Abstracts, Embase, Index Copernicus, EBSCO, African Index Medicus, JournalSeek, Journal Citation Reports/Science Edition, Directory of Open Access Journals (DOAJ), African Journal Online, Bioline International, Open-J-Gate and Pharmacy Abstracts

\section{INTRODUCTION}

Poisoning is a global public health concern. According to WHO data, in 2004, an estimated 346,000 people died worldwide from unintentional poisoning. Of these deaths, $91 \%$ occurred in low- and middle-income countries [1]. In Saudi Arabia, annual nationwide data on poisoning patterns are scarce and incomplete. Most previous studies conducted in Saudi Arabia 
that focused on poisoning were city- or regionspecific and failed to present the overall epidemiological characteristics and long-term trends in poisoning [2-7].

Activated charcoal has been used for the last century for gastric decontamination [8]. The amount of drug that adsorbs to the activated charcoal is dependent on the charcoal-to-drug ratio, with the optimal ratio proposed to be 10:1 [9]. As the dose of drug is rarely known, a standard dose of charcoal is normally given. The position statement for a single dose of activated charcoal suggests a dose of 10 to $25 \mathrm{~g}$ (or 0.5 $1.0 \mathrm{~g} / \mathrm{kg}$ ) of body weight in a child up to 1 year of age, 25 to $50 \mathrm{~g}$ (or $0.5-1.0 \mathrm{~g} / \mathrm{kg}$ ) in children 1 to 12 years of age, and 25 to $100 \mathrm{~g}$ in adolescents and adults. However, most children up to 12 years of age receive a dose of $1 \mathrm{~g} / \mathrm{kg}$ of body weight [10], although there is no single correct dose of activated charcoal.

Thus, there is a need to design a study to test the use of lower doses than the current standard dose of activated charcoal used in the treatment of acute drug poisoning, especially for drugs used in small doses (such as tricyclic antidepressants) to determine the appropriate dose of activated charcoal. It is evident from the literature that tricyclic antidepressants are identified as one of the most frequently ingested substances in self-poisoning along with paracetamol, benzodiazepines and alcohol [11]. There is also evidence that the number of deaths relative to the number of prescriptions issued is significantly higher for tricyclics than for other antidepressants [12].

The objective of this study was to assess the activated charcoal doses currently used in the management of acute drug poisoning and hence explore the possibility of using lower doses of activated charcoal, especially for drugs used in small doses.

\section{EXPERIMENTAL}

\section{Materials}

Amitriptyline and clomipramine (IS) from SigmaAldrich (St Louis, MO, USA) were kindly provided by toxicology unit, College of Medicine, King Saud University, Riyadh, Saudi Arabia. HPLCgrade acetonitrile was obtained from Panreac Chemicals (Barcelona, Spain), potassium dihydrogen phosphate and activated charcoal were procured from Winlab Ltd. (Maidenhead, Berkshire, UK) and water was produced in the laboratory by a Milli-Q purification system (Millipore Corp., Billerica, MA, USA). All other reagents used were at least of analytical grade.

\section{Method development}

\section{Instrumentation and chromatographic conditions}

High performance liquid chromatography (HPLC, Waters model 2695 Alliance separation module), equipped with UV detector. The chromatographic identification was carried out at room temperature $\left(25 \pm 1^{\circ} \mathrm{C}\right)$. The mobile phase consisted of acetonitrile and potassium dihydrogen phosphate buffer $(70 \mathrm{mM})$, in the ratio of $60: 40 \mathrm{v} / \mathrm{v}$, which was delivered isocratically at a flow rate of $1 \mathrm{ml} / \mathrm{min}$. Xterna $\circledR$ ms C18 SUM $(5 \mu \mathrm{m}, 3.9 \times 150 \mathrm{~mm})$ column was utilized to elute the compounds of interest at a $\lambda_{\max }=293 \mathrm{~nm}$ for the analysis of amitriptyline.

\section{Selection of mobile phase}

Different combinations of solvent systems of acetonitrile, buffer $\left(\mathrm{KH}_{2} \mathrm{PO}_{4}\right)$ : acetonitrile and formic acid: water and methanol: water: acetonitrile etc were tried in order to determine the best conditions for the separation and optimization of amitriptyline. The mobile phase consisting of acetonitrile and $70 \mathrm{Mm}$ potassium dihydrogen phosphate buffer $\left(\mathrm{KH}_{2} \mathrm{PO}_{4}\right)$ with $\mathrm{pH}$ adjusted to 4.5 in the ratio of $(60: 40 \% \mathrm{v} / \mathrm{v})$ was selected as it gave high resolution for amitriptyline with minimal tailing.

\section{Preparation of standard and calibration samples}

Stock standard solutions of $1 \mathrm{mg} / \mathrm{ml}$ amitriptyline and the internal standard (IS) clomipramine were individually prepared in acetonitrile. These stock solutions were kept frozen and used within 2 weeks. The working standard solution for each compound was prepared by serial dilution of the stock solution with acetonitrile. Calibration standards of plasma samples for UV detection were prepared by spiking the plasma with working solutions of amitriptyline to make the final concentrations of $10,15,20,25,30,35,40$, 45, 50 and $60 \mathrm{ng} / \mathrm{ml}$.

\section{Sample preparation}

Plasma samples kept at $-80^{\circ} \mathrm{C}$ were thawed for one hour and then vortexed for $30 \mathrm{~s}$ at room temperature before extraction to ensure homogeneity. Amitriptyline was extracted from the plasma with acetonitrile as the precipitation solvent. To $200 \mu \mathrm{l}$ of plasma containing 
amitriptyline, IS (110 ng/ml) was added in a 1.5$\mathrm{ml}$ capped centrifuge tube with vortex mixing. Acetonitrile $(140 \mu \mathrm{l})$ and $120 \mu \mathrm{l}$ of concentrated potassium phosphate solution $(1 \mathrm{~g} / \mathrm{ml})$ were added. The mixture was shaken and centrifuged at $2500 \times \mathrm{g}$ for $15 \mathrm{~min}$. The supernatant was transferred to another Eppendorf tube and $20 \mu \mathrm{l}$ of this was injected onto the column for the analysis of amitriptyline by RP-HPLC.

\section{Method validation}

Method validation was carried out according to $\mathrm{ICH}$ guidelines [13] in rat plasma in order to evaluate the method for linearity of response, accuracy, precision, recovery, limit of detection and quantification, selectivity, stability of analyte during processing, and storage.

\section{Linearity}

The linearity of an analytical method is its ability to elicit test results that are directly proportional to the concentration of analyte in samples within a given range. Thus, linearity refers to the relationship of concentration and assay measurement [13]. The linearity of the proposed method was evaluated by using calibration curves to calculate coefficient of correlation and intercept values.

\section{Precision, accuracy and recovery}

For precision and accuracy ( $n=6)$ of the method was determining by using calibration standard solution $(30 \mathrm{ng} / \mathrm{ml})$ of amitriptyline and results was expressed in terms of \% RSD. Recovery studies were carried out by applying the method to drug samples to which known amount of amitriptyline corresponding to higher concentration $60 \mathrm{ng} / \mathrm{ml}$ and lower concentration $10 \mathrm{ng} / \mathrm{ml}$. At each level, six determinations were performed.

\section{Limit of detection and of quantification (LOD and $L O Q$ )}

For determination of LOD and LOQ, blank plasma samples (without AMT and IS) were injected in triplicate for peak area calculations. LOD and LOQ were determined from the slope (S) of the calibration curve and SD of the response for the blank samples as follows: LOD $=3.3 \times \mathrm{SD} / \mathrm{S}$; and $\mathrm{LOQ}=10 \times \mathrm{SD} / \mathrm{S}$.

\section{Selectivity and specificity}

The selectivity of the method was checked by injecting solution of amitriptyline. It was observed that sharp peaks for IS and amitriptyline occurred at retention times of 4.5 and $6.15 \mathrm{~min}$, respectively. These peaks were not present in the chromatogram of blank plasma. The specificity of the method was assessed by comparing chromatograms obtained from drug standards with that obtained from plasma of animals. The retention times of the drug standards and the drugs from treated animals were found to be same, indicating the method was specific and selective because of no interference was found in plasma (Fig 1A - D).

\section{Stability}

The stability (short term) of standard and amitriptyline sample solutions was carried out by analyzing the drug after 24 and $48 \mathrm{~h}$ at room temperature and $-20{ }^{\circ} \mathrm{C}$ against fresh standard solutions. Long-term stability was evaluated after storing samples at $-80{ }^{\circ} \mathrm{C}$ for 30 days. All stability experiments were carried out against freshly spiked calibration standards.

\section{Method application}

\section{Animals}

Albino male Wistar rats weighing approximately $200 \pm 20 \mathrm{~g}$ were obtained from the Experimental Animal Care Center, College of Pharmacy, King Saud University, Riyadh, Saudi Arabia. The animals were kept under controlled environmental conditions $\left(25{ }^{\circ} \mathrm{C}\right.$ and a $12 \mathrm{~h}$ light/dark cycle). Animals were given free access to pulverized standard rat pellet food and tap water. The protocol of this study has been approved (clearance number 021015-0618; March 10, 2013) by Research Ethics Committee of College of Pharmacy, King Saud University, Riyadh, Saudi Arabia, and the animals were handled in accordance with the Guide for the Care and Use of Laboratory Animals by National Institute of Health[14].

\section{Experimental design}

The animals were divided into four groups of eight animals each. Group I served as positive control received only $1 \mathrm{ml}$ of amitriptyline (2.5 $\mathrm{mg} / \mathrm{ml}$ ) by oral route. Group- II was administered with $1 \mathrm{ml}$ of amitriptyline $(2.5 \mathrm{mg} / \mathrm{ml})$ and after ten minutes $1 \mathrm{ml}$ of activated charcoal $(50 \mathrm{mg} / \mathrm{ml}$, i.e., quarter dose of the standard dose of the activated charcoal) by oral route. Group III was administered $1 \mathrm{ml}$ of amitriptyline $(2.5 \mathrm{mg} / \mathrm{ml})$ and after ten minutes $1 \mathrm{ml}$ of activated charcoal $(100 \mathrm{mg} / \mathrm{ml}$, i.e., half dose of the standard dose of the activated charcoal). Group IV served as standard control and was given $1 \mathrm{ml}$ of amitriptyline $(2.5 \mathrm{mg} / \mathrm{ml})$ and after ten $\mathrm{min}$, 

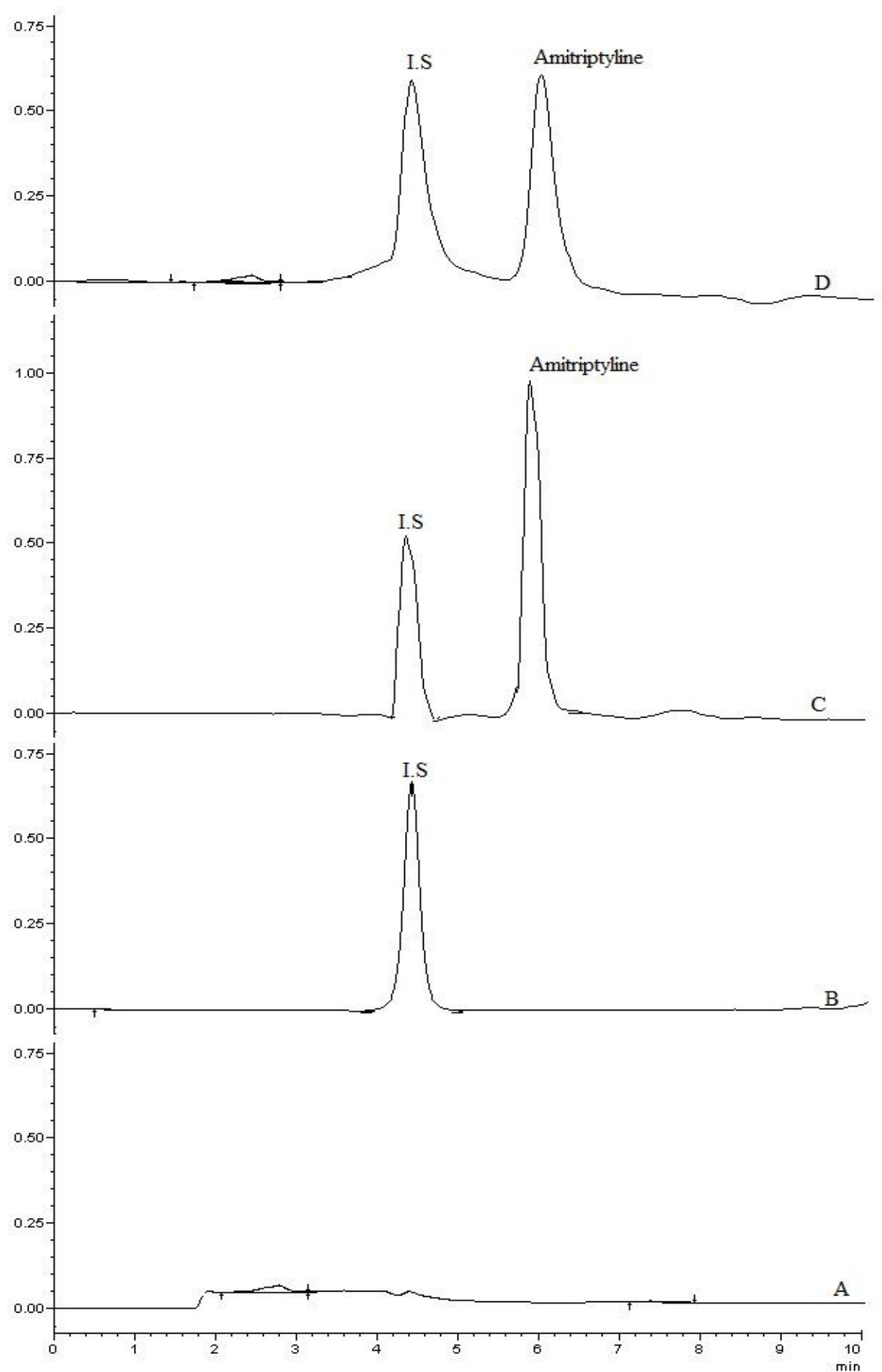

Figure 1: HPLC chromatogram of (A) blank plasma, (B) plasma spiked with internal standard (I.S), (C) plasma sample from the calibration curve of amitriptyline $(20 \mathrm{ng} / \mathrm{ml}$; Rt, $6.15 \mathrm{~min})$ and I.S (Rt $4.5 \mathrm{~min})$, and (D) plasma sample from rat administered with amitriptyline $(2.5 \mathrm{mg} / \mathrm{kg}, \mathrm{p.o})$

$1 \mathrm{ml}$ of activated charcoal $(200 \mathrm{mg} / \mathrm{ml}$ dose, i.e.; the standard dose of the activated charcoal). Standard dose of the activated charcoal have been measured on the basis of the activated charcoal dose, $1 \mathrm{~g} / \mathrm{kg}$ of the body weight. After two hours of dosing the animals were anesthetized and blood was collected from heart. Plasma was separated by centrifugation at 2500 $\times \mathrm{g}$ for $10 \mathrm{~min}$ and was transferred to pre-labeled eppendorf tubes for subsequent analysis of amitriptyline concentration using the developed method.

\section{Statistical analysis}

Data were statistically analyzed using the statistics program (Sigma plot V12) and are given as mean \pm SEM. Differences between 
groups were determined by one-way analysis of variance (ANOVA) using Student-Newman-Keuls method for all pair-wise multiple comparison procedure. $P<0.05$ was considered statistically significant.

\section{RESULTS}

The method was developed and validated according to $\mathrm{ICH}$ guidelines. The linear regression analysis indicated a good linearity over a wide concentration range $(10-60 \mathrm{ng} / \mathrm{ml})$ with regard to peak area. The mobile phase compositions were prepared with appropriate ratios of acetonitrile, water and buffer (70 Mm). The adjustment of $\mathrm{pH} 4.5$ was made using orthophosphoric acid. It was detected that the best determination of amitriptyline was attained with a mobile phase composed of acetonitrile and buffer $(\mathrm{pH} 4.5)$ at $(60: 40 \% \mathrm{v} / \mathrm{v})$ ratio and a flow rate of $1 \mathrm{ml} / \mathrm{min}$.

\section{Calibration curve and linearity}

The test was test on ten concentrations (10, 15, $20,25,30,35,40,45,50,60 \mathrm{ng} / \mathrm{ml}$ ) and was repeated three times for each concentration. No significant difference was observed in the slopes of standard curves. The observed straight line equation was, $y=0.033 x+0.0056$ with $r^{2}$ value of $>0.9996$.

\section{Precision, accuracy and recovery}

The precision of the developed analytical method was done by measuring the standard amitriptyline concentration (30 ng/ml). Measurement was done repeatedly six times for each injection. The relative standard deviation (RSD of the results was found to be 0.51 , while the percentage recovery was found to be $100.056 \pm 0.51 \%$, as shown in (Table 1$)$.
Table 1: Concentration of amitriptyline (30 ng/ml) injected and mean recovery

\begin{tabular}{lcc}
\hline S/no. & $\begin{array}{c}\text { Measured } \\
\text { concentration } \\
\text { (ng/ml) }\end{array}$ & Recovery (\%) \\
\hline 1 & 30.07 & 100.23 \\
2 & 30.12 & 100.40 \\
3 & 29.87 & 99.57 \\
4 & 30.23 & 100.80 \\
5 & 29.98 & 99.93 \\
6 & 29.83 & 99.43 \\
Mean & 30.017 & 100.05 \\
$\%$ RSD & 0.153 & 0.51 \\
\hline
\end{tabular}

The accuracy of the assay method was evaluated at two concentration levels of amitriptyline, i.e., higher concentration $(60 \mathrm{ng} / \mathrm{ml})$ and lower concentration $(10 \mathrm{ng} / \mathrm{ml})$ and repeated six times for each injection. The percentage of recoveries and \% RSD were calculated from the slope and $y$-intercept of the calibration curve. The recovery values obtained were in the range of 98.3 to $100.85 \%$ confirming accuracy of the developed method (Table 2). The percentage recovery of the lowest concentration was $99.71 \pm$ $0.99 \%$ and that of the highest concentration was $100.001 \pm 0.185 \%$.

\section{Limits of detection (LOD) and of quantification (LOQ)}

The signal-to-noise ratio of 3.3:1 and 10:1 were considered as LOD and LOQ and were found to be 0.40 and $1.0 \mathrm{ng} / \mathrm{ml}$, respectively.

\section{Selectivity and specificity}

The results indicated that there was no overlap between the analyte and the rest materials, and the retention time of amitriptyline was found to be $6.15 \mathrm{~min}$. The specificity of the method was shown by the lack of interfering endogenous

Table 2: Recovery of the developed HPLC method $(n=6)$

\begin{tabular}{lcccc}
\hline S/no. & $\begin{array}{c}\text { Lowest } \\
\text { concentration } \\
(\mathbf{1 0} \mathbf{~ n / m l )}\end{array}$ & Recovery (\%) & $\begin{array}{c}\text { Highest } \\
\text { concentration } \\
\text { (60 } \mathbf{~ n g / m l ) ~}\end{array}$ & Recovery (\%) \\
\hline 1. & 10.33 & 99.15 & 60.1 & 99.7 \\
2. & 10.31 & 98.3 & 60.32 & 99.87 \\
3. & 10.37 & 100.85 & 60.6 & 100.07 \\
4. & 10.33 & 99.15 & 60.76 & 100.19 \\
5. & 10.36 & 100.43 & 60.72 & 100.16 \\
6. & 10.36 & 100.43 & 60.51 & 100.01 \\
Mean & 10.34 & 99.71 & 60.5 & 100.00 \\
\% RSD & 0.02 & 0.99 & 0.25 & 0.185 \\
\hline
\end{tabular}


plasma components in the chromatograms of screened plasma batches.

\section{Stability}

Stability (short-term) was validated for 6 and 48 $\mathrm{h}$, both at room temperature. Long-term stability was evaluated after storage of the test samples at $-80^{\circ} \mathrm{C}$ for 30 days. All stability experiments were carried out against freshly spiked calibration standards.

\section{Analysis of amitriptyline in plasma by the developed method}

The developed HPLC method was successfully used to quantify amitriptyline in plasma samples, following oral administration of drug and activated charcoal. The resulting drug concentrations measured in plasma collected after $2 \mathrm{~h}$ of dosing. The concentrations of drug obtained in plasma in all four animal groups are presented in (Table 3 ). One way analysis of variance (ANOVA) was used to interpret the results obtained after plasma analysis in all groups and the results were presented well in (Table 3).
The statistical results are also displayed in Table 4 in terms of degree of freedom, $p$-value, etc.

The statistical size of the effect was also be calculated as in Eq 1.

$r^{2}=\eta^{2}=S S_{\text {amonggroup }} / S_{\text {total }}=3949.375 / 6485.220$

$=0.609$.

This value $\left(r^{2}=0.609\right)$ can also be explained on the basis of the guidelines by Cohen, which stipulates that $0.1,0.25$ and 0.4 represents small, medium and large effect sizes, respectively. Therefore, it is evident from the $r^{2}$ value that it is a size of a large impact. Student-Newman-Keuls method was used to identify the sources of these differences for multiple comparison tests, and the results are shown in Table 5.

The results of statistics indicated that there were significant differences between the average concentration of amitriptyline without the use of activated charcoal, and the average concentration of amitriptyline when the activated charcoal concentrations i.e. $200 \mathrm{mg} / \mathrm{ml}, 100$ $\mathrm{mg} / \mathrm{ml}$ respectively, were used. Fig. 2 illustrates the differences between the arithmetic mean concentrations of the drug.

Table 3: Drug concentrations in blood sample following administration of $2.5 \mathrm{mg}$ mitriptyline to rats

\begin{tabular}{lllll}
\hline \multirow{2}{*}{$\begin{array}{l}\text { Amitriptyline } \\
\mathbf{m g})\end{array}$} & $\mathbf{( 2 . 5}$ & \multicolumn{4}{l}{ Blood drug concentration $\mathbf{n g} / \mathbf{m l} \mathbf{n} \mathbf{= 8})$} \\
\cline { 2 - 5 } & Group-I & Group-II & Group-III & Group-IV \\
\hline & 41.2 & 36.5 & 35.5 & 19.6 \\
& 42.9 & 44.3 & 20.4 & 13.8 \\
& 23.0 & 39.4 & 14.4 & 13.0 \\
& 24.9 & 39.8 & 16.8 & 13.1 \\
& 23.5 & 22.0 & 15.3 & 9.3 \\
& 52.9 & 51.2 & 19.9 & 13.6 \\
Mean \pm SD & 25.7 & 30.8 & 9.0 & 2.5 \\
& 58.8 & 36.1 & 18.9 & 10.8 \\
\hline
\end{tabular}

Table 4: Results of statistical analysis

\begin{tabular}{lccccc}
\hline Source of variation & DF & Sum of squares & Mean square & $\boldsymbol{F}$-value & $\boldsymbol{P}$-value \\
\hline Between Groups & 3 & 3949.375 & 1316.458 & 14.536 & $<0.001$ \\
Residual & 28 & 2535.845 & 90.566 & & \\
Total & $\mathbf{3 1}$ & $\mathbf{6 4 8 5 . 2 2 0}$ & & & \\
\hline
\end{tabular}

Table 5: Student-Newman-Keuls Method for all pair-wise multiple comparison procedures

\begin{tabular}{lccccc}
\hline Comparison & Differences of means & $\mathbf{P}$ & $\mathbf{q}$ & $\boldsymbol{p}$ & $\boldsymbol{P}<\mathbf{0 . 0 5 0}$ \\
\hline Row 2 vs. Row 4 & 25.550 & 4 & 7.594 & $<0.001$ & Yes \\
Row 2 vs. Row 3 & 18.700 & 3 & 5.558 & $<0.002$ & Yes \\
Row 2 vs. Row 1 & 0.900 & 2 & 0.267 & $<0.851$ & No \\
Row 1 vs. Row 4 & 24.650 & 3 & 7.326 & $<0.001$ & Yes \\
Row 1 vs. Row 3 & 17.800 & 2 & 5.290 & $<0.001$ & Yes \\
Row 3 vs. Row 4 & 6.850 & 2 & 2.036 & $<0.161$ & No \\
\hline
\end{tabular}




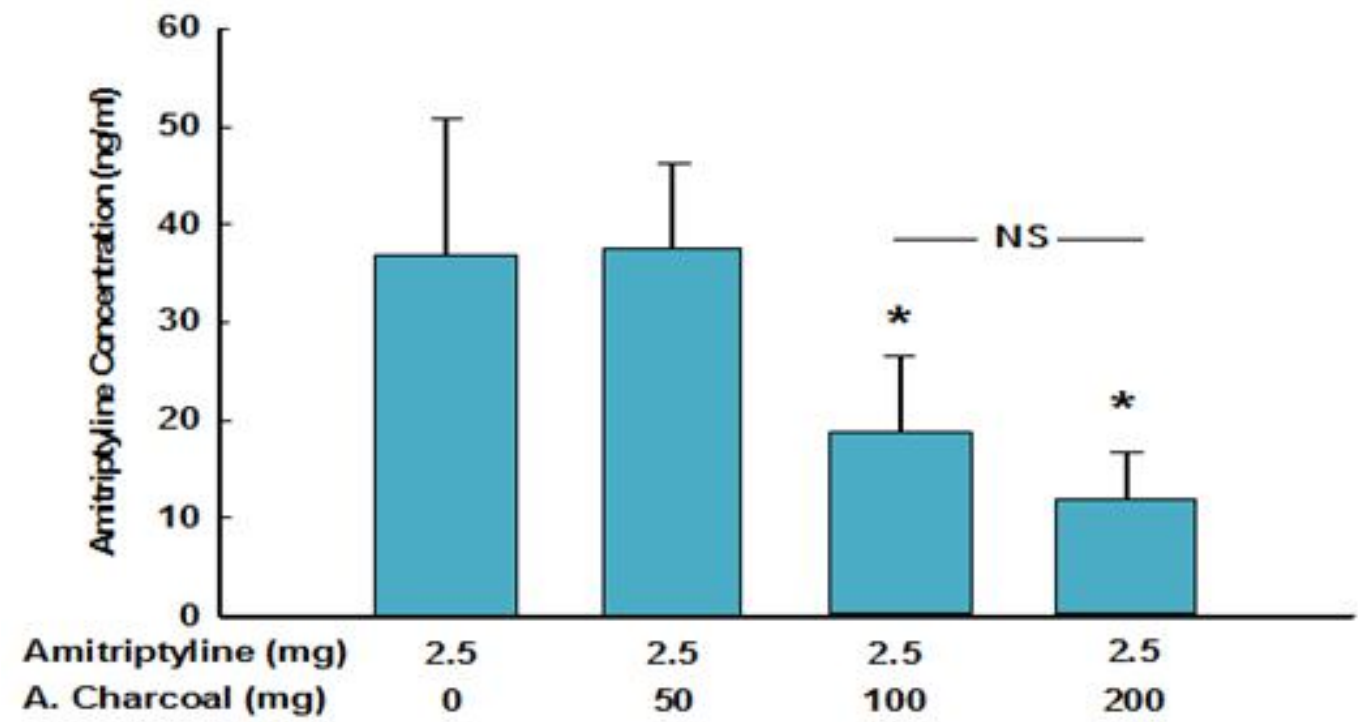

Figure 2: Statistical graph explains the differences between the arithmetic mean concentrations; ${ }^{*} p<0.05,{ }^{* *} p$ $<0.01,{ }^{* * *} p<0.001$

It is clear from the above plot that there is no statistical difference between the mean concentration of amitriptyline when 100 and 200 $\mathrm{mg} / \mathrm{ml}$ activated charcoal were used.

\section{DISCUSSION}

In the present study, LOD and LOQ were 0.40 and $1.0 \mathrm{ng} / \mathrm{ml}$, respectively, which indicate an adequate sensitivity of the developed method. Selectivity was performed to differentiate amitriptyline from rest of the material present in the sample and to determine the retention time of amitriptyline. The retention time of the amitriptyline was $6.15 \mathrm{~min}$ in all samples, which means that there was no overlap between the analyte and the rest materials. The stability experiments results were always well within \pm 15 $\%$ of deviation, and thus indicates that no degradation of amitriptyline occurred under the defined conditions.

The results of the analysis indicated that, using the half of the standard dose $(100 \mathrm{mg} / \mathrm{ml})$ of the activated charcoal gave comparable effect to that of the standard dose $(200 \mathrm{mg} / \mathrm{ml})$ in reducing the concentration of amitriptyline in the blood as evidenced by the plasma concentration of drug as indicated in (Table 3 ). On the other hand, using quarter of the standard dose $(50 \mathrm{mg} / \mathrm{ml})$ of activated charcoal did not produce a significant effect in reducing the drug concentration in blood after $2 \mathrm{~h}$ of dosing.

The differences in the mean values among the treatment groups are greater than would be expected by chance; there is a statistically significant difference $(p<0.001)$. Since the level of significance calculated $(p<0.001)$ is smaller than the significance level of statistical study (0.05), there was no significant differences for the average concentrations of amitriptyline between the control group and the other two groups of focus those were given $200 \mathrm{mg} / \mathrm{ml}$ and $100 \mathrm{mg} / \mathrm{ml}$ of activated charcoal (Table 4).

There was statistically significant difference between the mean concentration of amitriptyline when 50 and $200 \mathrm{mg} / \mathrm{ml}$ activated charcoal concentration was used; same was observed when 50 and $100 \mathrm{mg} / \mathrm{ml}$ activated charcoal concentration was used. However, no statistically significant difference was found when 100 and $200 \mathrm{mg} / \mathrm{ml}$ activated charcoal concentrations were used. No statistically significant differences between the average concentration of Amitriptyline without the use of activated charcoal, and the average concentration of Amitriptyline when $50 \mathrm{mg} / \mathrm{ml}$ of activated charcoal concentration was used.

It was also observed that a small dose of activated charcoal $(100 \mathrm{mg} / \mathrm{ml})$ produced an effect that was comparable to that of the highest standard dose of the activated charcoal (200 $\mathrm{mg} / \mathrm{ml}$ ) in terms of reducing the toxic concentration of amitriptyline in the blood of rats. We also note that the use of half of the minimum dose of the standard dose of the activated charcoal, $50 \mathrm{mg} / \mathrm{ml}$ had a very limited effect in reducing the toxic concentration of the drug. 


\section{CONCLUSION}

The developed RP-HPLC method enables determination of amitriptyline with good separation and resolution of the chromatographic peaks. Furthermore, using half of the standard dose of activated charcoal produced a comparable effect to the standard dose in reducing blood drug concentration. The method is simple and accurate, and may be considered for routine analysis of amitriptyline in biological samples, raw materials and pharmaceutical formulations, as well as for therapeutic drug monitoring in clinical practice.

\section{ACKNOWLEDGEMENT}

The authors are thankful to Toxicology Unit, College of Medicine, King Saud University, Riyadh, Saudi Arabia, for providing reference samples and other technical support for the research work. Also, the authors are grateful to the College of Pharmacy Research Center and the Deanship of Scientific Research, King Saud University for the financial support.

\section{REFERENCES}

1. World Health Organization. The global burden of disease: 2004 update. [http://www.who.int/healthinfo/global_burden_disease /GBD_report_2004update_full.pdf?ua=1, [Accessed on 13 May 2014]. WHO2008.

2. Al-Shehri MA. Pattern of childhood poisoning in abha city - southwestern saudi arabia. J Family Community Med. 2004; 11: 59-63.
3. Izuora GI, Adeoye A. A seven-year review of accidental poisoning in children at a Military Hospital in Hafr Al Batin, Saudi Arabia. Ann Saudi Med. 2001; 21: 13-15.

4. Moazzam M, Al-Saigul AM, Naguib M, Al Alfi MA. Pattern of acute poisoning in Al-Qassim region: a surveillance report from Saudi Arabia, 1999-2003. East Mediterr Health J. 2009; 15: 1005-1010.

5. Al-Barraq A, Farahat F. Pattern and determinants of poisoning in a teaching hospital in Riyadh, Saudi Arabia. Saudi Pharm J. 2011; 19: 57-63.

6. Saddique A. Poisoning in Saudi Arabia: ten-year experience in King Khaled University Hospital. Ann Saudi Med. 2001; 21: 88-91.

7. Al Hazmi AM. Patterns of accidental poisoning in children in Jeddah, Saudi Arabia. Ann Saudi Med. 1998; 18: 457-459.

8. Holt LE, Jr., Holz PH. The Black Bottle. A Consideration of the Role of Charcoal in the Treatment of Poisoning in Children. J Pediatr. 1963; 63: 306-314.

9. Levy G, Tsuchiya T. Effect of activated charcoal on aspirin absorption in man. Part I. Clin Pharmacol Ther. 1972; 13: 317-322.

10. Chyka PA, Seger D, Krenzelok EP, Vale JA. American Academy of Clinical $T$, European Association of Poisons C, et al. Position paper: Single-dose activated charcoal. Clin Toxicol (Phila). 2005; 43: 6187.

11. Buckley NA, Whyte IM, Dawson AH, McManus PR, Ferguson NW. Self-poisoning in Newcastle, 19871992. Med J Aust. 1995; 162: 190-193.

12. Henry JA, Alexander CA, Sener EK. Relative mortality from overdose of antidepressants. BMJ. 1995; 310: 221-224.

13. Guidance for Industry: Q2B Validation of Analytical Procedures: Methodology, ICH Harmonised Tripartite Guideline. November 1996.

14. Guide for the Care and Use of Laboratory Animals. 8th edn. Washington (DC) 2011. 